\title{
Silicose nas pedreiras: a sutil diferença entre conhecer e adoecer. Intervenções em Saúde do Trabalhador na explotação de rochas ornamentais
}

\section{Silicosis in quarries: the subtle difference between knowing and fall ill. Interventions in Workers' Health in the exploitation of ornamental stones}

\author{
Roberta Guio Azevedo' (1), Gabriel Eduardo Schütz² (1) \\ 'Instituto de Estudos em Saúde Coletiva, Universidade Federal do Rio de Janeiro (UFRJ) - Rio de Janeiro, RJ, Brasil. \\ ${ }^{2}$ Instituto de Estudos em Saúde Coletiva, Universidade Federal do Rio de Janeiro, Rio de Janeiro, RJ. Brasil.
}

Como citar: Azevedo RG, Schütz GE. Silicose nas pedreiras: a sutil diferença entre conhecer e adoecer. Intervenções em Saúde do Trabalhador na explotação de rochas ornamentais. Cad Saúde Colet, 2021;29(1):67-76 . https://doi.org/10.1590/1414-462X202129010081

\begin{abstract}
Resumo
Introdução: Trabalhadores nas pedreiras de rochas ornamentais estão expostos a vários riscos ocupacionais, no entanto destacamos a ocorrência da principal doença pulmonar associada à inalação de partículas de sílica. Objetivo: Apresentar as principais intervenções em saúde do trabalhador aplicadas na prevenção de exposições ocupacionais à poeira contendo sílica livre em duas pedreiras da região noroeste do Espírito Santo. Método: Observação participante dos processos de trabalho em duas pedreiras, realizada em dois anos diferentes, complementada com análise documental. Resultados: É possível distinguir as funções mais expostas à inalação de sílica e modificar o processo de trabalho introduzindo tecnologia capaz de minimizar a formação de poeira. $O$ envolvimento de empresários, trabalhadores organizados e do poder público é essencial para o controle de emissão de particulados nas pedreiras. Conclusão: Observa-se a necessidade de incentivos para o investimento em capacitação de mão de obra qualificada e em tecnologias de ponta no setor, uma mudança que urge em prol da saúde do trabalhador na produção de rochas ornamentais no combate à silicose.
\end{abstract}

Palavras-chave: silicose; saúde do trabalhador; prevenção de acidentes; mineração.

\begin{abstract}
Background: Workers in ornamental stone quarries are exposed to several occupational hazards; however, it is highlighted the occurrence of the main lung disease associated with inhalation of silica particles. Objective: To present the main interventions in worker's health applied in the prevention of occupational exposures to dust-containing free silica in two quarries in the northwestern region of Espírito Santo. Method: Observation participant of the work processes in two quarries carried out in two different years, complemented with documentary analysis. Results: It is possible to distinguish the functions most exposed to the inhalation of silica and modify the work process by introducing technology capable of minimizing the formation of dust. The involvement of entrepreneurs, organized workers, and public power is essential for controlling the emission of particulates in quarries. Conclusion: There is a
\end{abstract}

Trabalho realizado no Município de Barra de São Francisco e Município de Vila Pavão (ES), Brasil.

*Correspondência: Roberta Guio Azevedo. E-mail: robertaguio1969@gmail.com

Fonte de financiamento da pesquisa: Aluna Bolsista CAPES.

Não possui conflito de interesses.

Recebido em: Fev. 26, 2019. Aprovado em: Mar. 02, 2020
Este é um artigo publicado em acesso aberto (Open Access) sob a licença Creative Commo Attribution, que permite uso, qualquer meio, sem restrições desde que o trabalho original seja corretamente citado. 
need for incentives to invest in skilled labor and state-of-the-art technologies in the sector, a change that is urgent for the health of workers in the production of ornamental stones in the fight against silicosis.

Keywords: silicosis; worker's health; accidents prevention; mining.

\section{INTRODUÇÃO}

A silicose é considerada a mais antiga, mais grave e mais prevalente das doenças pulmonares relacionadas à inalação de poeiras minerais. É uma doença pulmonar crônica incurável, com evolução progressiva e irreversível que pode determinar incapacidade, invalidez, aumento da suscetibilidade à tuberculose, podendo causar o óbito'.

A exposição mais comum a estas poeiras é no ambiente laboral, pelo que é considerada uma doença ocupacional, com toxicidade de longo prazo $^{2}$. A mineração, mais especificamente a extração de rochas, é um dos processos com maior risco ocupacional ${ }^{3}$. Uma vez detectada, o trabalhador deve ser afastado da atividade de ris $\mathrm{CO}^{4}$, avaliado quanto ao grau de comprometimento de sua saúde, periciado quanto à incapacitação e, ao longo da vida, acompanhado em sua evolução e intercorrência clínica por médicos e outros profissionais de saúde ${ }^{5}$.

A indústria de extração de granito desempenha um papel de grande importância no cenário econômico no Espírito Santo, constituindo-se o maior polo de extração e beneficiamento de rochas ornamentais do país.

O granito é uma rocha ornamental muito utilizado na cadeia produtiva do setor de construção, o processo de explotação de granitos ornamentais - retirada, corte e transporte de bloco - é uma atividade que contribui para a expansão das exportações capixabas, além de gerar cerca de 30 mil empregos diretos e 60 mil indiretos ${ }^{6}$. O Sindicato dos Trabalhadores do Mármore e Granito do Espírito Santo (Sindimármore) estima que 8 mil dos trabalhadores formalizados estão sindicalizados.

Segundo dados do Instituto Estadual de Meio Ambiente e Recursos Hídricos no estado do Espírito Santo (IEMA), existem até o ano de 2017 mais de 2.000 empresas com atividade de extração minerária na região noroeste do estado em processo de licenciamento através de obtenção de licença prévia, licença de instalação, licença de operação ou renovação de licença.

Grande parte da prevalência de silicose entre trabalhadores da explotação de granito encontra a sua determinação no descaso com a saúde do trabalhador desse setor produtivo até o ano de 20047, ano em que o Ministério de Trabalho e Emprego (MTE), por meio da Portaria no 99-04, incluiu o item "7", no título "Sílica Livre Cristalizada", do Anexo no 12, da Norma Regulamentadora no 15 - "Atividades e operações insalubres"; ; ano que entrou em vigor a Política Nacional de Segurança e Saúde do Trabalhador, do Ministério da Saúde9; ano em que a Fundacentro e os Ministérios do Trabalho e Emprego, Saúde, Previdência Social, Departamento de Justiça e OIT/ Brasil assinaram memorandos de entendimento bilaterais com o objetivo de promover o avanço do Programa Nacional de Eliminação da Silicose ${ }^{10}$. A reforma da NR15, embora focada nas atividades de jateamento com areia, facilitou a negociação de normas de segurança nas pedreiras capixabas. Adicionalmente, o fato de a silicose ser uma doença que se manifesta clinicamente em forma crônica dificulta estabelecer relações entre a sua incidência e a matriz de exposição ocupacional (MEO) ${ }^{11}$, trazendo a incerteza da futura ocorrência da doença para muitos trabalhadores.

Entre os setores que apresentam maior risco ocupacional à silicose estão a indústria extrativa, incluindo mineração subterrânea e a céu aberto, com as atividades de perfuração de rochas, de extração e o beneficiamento de minérios e rochas que contenham o mineral ${ }^{5}$.

Neste artigo são apresentadas algumas das ações que visam minimizar a poeira de sílica livre no processo de lavra de rochas ornamentais (granito) a céu aberto em duas pedreiras da mesma empresa mineradora na região noroeste do Espírito Santo, descrevendo os processos de trabalho em dois momentos de intervenção diferentes. 


\section{MÉTODO}

O estudo foi realizado em pedreiras dos municípios de Barra de São Francisco e de Vila Pavão. Ambos possuem um número significativo de lavras registradas ${ }^{12}$, com diversas pedreiras em operação, incluindo as clandestinas ${ }^{13}$.

Aos fins desta pesquisa, foram desenvolvidos procedimentos de observação participante ${ }^{14}$ nas duas pedreiras selecionadas, escolha determinada pela modernização do processo de explotação com anuência da empresa para a realização da pesquisa.

Tais procedimentos consistiram em: (i) imersão no ambiente de trabalho; (ii) reconhecimento das características do local, das relações formais e informais de trabalho; observação do processo de trabalho; (iii) levantamento de informações sobre características técnicas específicas; (iv) registro fotográfico; e (v) reflexão analítica e integradora do observado.

As visitas às pedreiras foram realizadas em dois períodos diferentes, totalizando 40 dias, entre setembro de 2008 e maio de 2009; e uma semana de visita em 2016, uma vez incorporados os novos cenários tecnológicos de produção. Informações complementares foram obtidas em publicações científico-acadêmicas, em bases de dados oficiais e em documentações cedidas pelo Sindimármore.

\section{RESULTADOS}

\section{Descrição do processo de extração de rochas ornamentais}

Atualmente, a grande maioria das pedreiras de granito para fins ornamentais utiliza o método de lavra em rocha a céu aberto, com sistema de bancada alta, para a retirada do bloco. O processo de extração começa com a escolha da rocha ${ }^{15}$ e segue as etapas até a retirada do bloco da praça de trabalho (Figura 1).

A segurança no ambiente de trabalho em uma frente de lavra começa pela seleção do pessoal, o qual deve ser composto por profissionais capacitados com qualificações específicas para operar as máquinas e ferramentas que devam ser empregadas.

Comumente, o número de trabalhadores por pedreira é, em média, de 90 , podendo variar entre dois e seis turnos diferenciados. No caso das pedreiras estudadas, constatou-se que a de Barra de São Francisco emprega 135 funcionários, ao tempo que a pedreira de Vila Pavão emprega 106. Ambas operam 24 horas por dia, 7 dias por semana, com seis equipes divididas em turnos em escala diferenciados, sendo que $81 \%$ dos funcionários encontram-se em atividade de segunda a sexta.

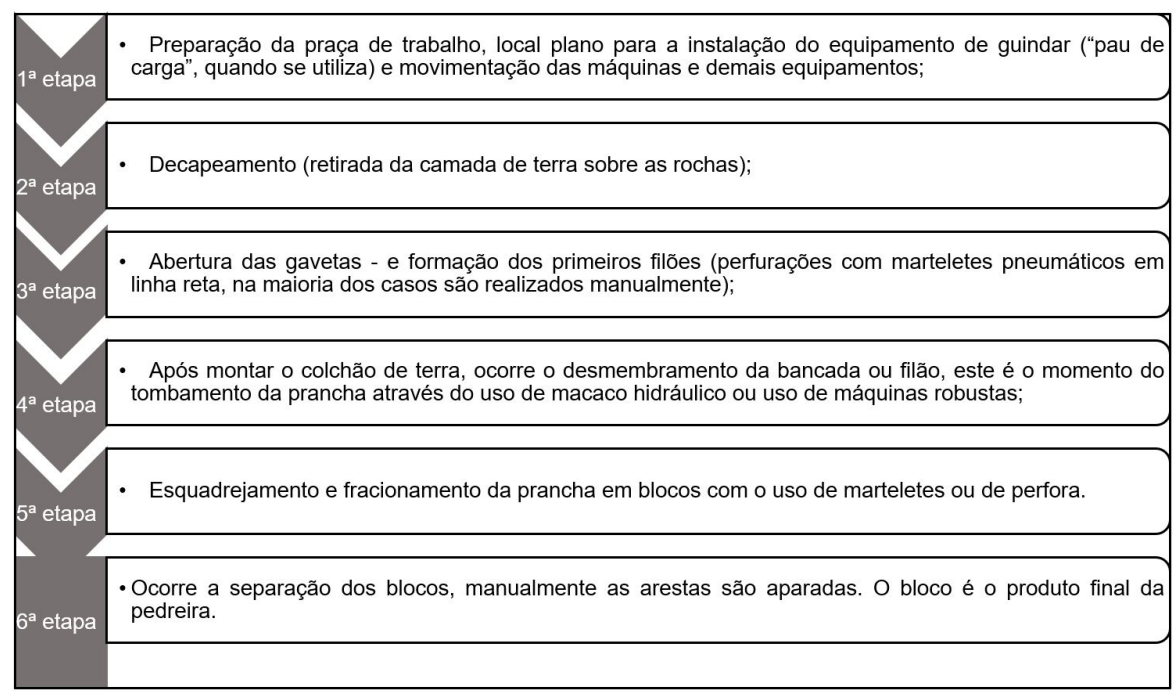

Figura 1. Etapas do processo de extração. 
As funções dos trabalhadores nas pedreiras seguem a Classificação Brasileira de Ocupação (MTE), iniciando pela função de gestor, encontramos: 1 ) encarregado geral - responsável pelo serviço geral, prático e administrativo; 2) subencarregado - que faz a parte de campo, distribuído nas três atividades: 2.1 ) cortador - responsável pelo esquadrejamento; 2.2 ) coordenador de equipe - responsável por todo o trabalho de campo executado na pedreira; 2.3) classificador seleciona os produtos para comércio interno ou exportação;3) técnico industrial de mineração - trabalha com tecnologia de lavra, estabilidade do maciço rochoso, englobando desmonte, perfuração e fio diamantado; 4) técnico em segurança do trabalho - acompanha as atividades executadas na pedreira relativas a segurança do trabalho, palestras e treinamentos periódicos; 5) engenheiro de segurança do trabalho - orienta e fiscaliza, em tempo parcial, as atividades relacionadas à segurança do trabalho; 6 ) encarregado de fogo, cabo de fogo ou blaster - faz o trabalho de apoio geral na praça de trabalho e executa a função específica de detonação; o paiol de explosivo é de responsabilidade dele; 7) marteleteiro - opera o martelete mecânico pneumático umidificado, para furação da rocha vertical com profundidade de até 15 metros e horizontal para passagem dos cabos de fio diamantado; 8) marineiro ou operador de perfuratriz ou bancadista - opera a perfuratriz pneumática com processo umidificado (máquina de 2 a 4 martelos que faz a mesma função do marteleteiro, sendo mecanizada); 9) operador de perfora, perfurador de filão ou fundo furo - utiliza a perfuratriz pneumática com processo umidificado com profundidade de até $3,20 \mathrm{~m}$ para perfurar o filão previamente marcado pelo cortador; esta função se subdivide em: 9.1) jet flame - operador de maçarico, apenas utilizado para cortar e isolar o fio; 9.2) operador de girodrill - executa a perfuração com equipamento hidráulico e umidificado na prancha de no máximo 2,60 m de profundidade; 10) fiolista - opera a máquina de fio diamantado; é responsável por pescar o fio, passar, montar a máquina e realizar o corte, e caso necessário deve também montar a torre (de cano); 11) operador de ferri; 12) operador de máquinas - dirige a pá mecânica, escavadeira hidráulica e pá carregadeira 988b (eleva o bloco de até 30 t em uma rampa específica para carregar a carreta) nas pedreiras estudadas; esse equipamento substitui o"pau de carga"; 13) eletricista; 14) mecânico - essas duas funções compõem a turma de apoio para uso da máquina com martelete pneumático; 15) motorista de Terex ou fora de estrada; 16) motorista geral - faz o abastecimento das máquinas pesadas e compressores além de transportar insumos para a frente de trabalho; e 17) soldador.

Os processos supracitados associam-se com diferentes tipos de riscos à saúde dos trabalhadores, incluindo os dedicados a operações transversais, podendo citar-se a exposição ao ruído; a exposição a vibrações em mãos e braços; o risco ergonômico, bem como o risco de acidente grave (cortes, quedas, choque elétrico, mutilações e queimaduras dentre outros) ${ }^{16}$. No entanto, as funções mais suscetíveis a riscos toxicológicos relacionados à inalação de poeira contendo sílica ${ }^{7}$ são 7 e correspondem a aproximadamente $40 \%$ das funções de uma frente de lavra, sendo que 5 dessas funções estão diretamente em contato com o particulado e correspondem a $61 \%$ dos trabalhadores de uma frente de lavra expostos à inalação de sílica livre cristalina ${ }^{17}$ (Figura 2).

As principais diferenças encontradas entre a primeira visita às pedreiras, em 2009, e a última, em 2016, foram relativas ao investimento em tecnologia. O processo produtivo continua o mesmo, porém constataram-se investimentos objetivando mudanças tecnológicas de processos com novas funções, como operador de perfuratriz, operador de girodrill e fiolista, gerando uma redução considerável de trabalhadores na frente de lavra. Havia também nas empresas sinalização de segurança alertando quanto à exposição ao pó de pedra. Observamos também uma relação mais estreita entre o Sindimármore e as empresas da região, após 2014, com a obrigatoriedade de as empresas registrarem a Comunicação de Acidente de Trabalho (CAT) no sindicato, o que levou a uma mudança da cultura de emissão, expondo o crescente número de ocorrência de acidentes e de silicose no setor (Tabela 1).

\section{Intervenções em Saúde do Trabalhador: Objetivando a prevenção da silicose}

Na prevenção contra a silicose não há lugar para processos arcaicos de produção, a prevalência de novos casos aumenta todos os anos. Hunter ${ }^{18}$ sublinha que a silicose é uma 


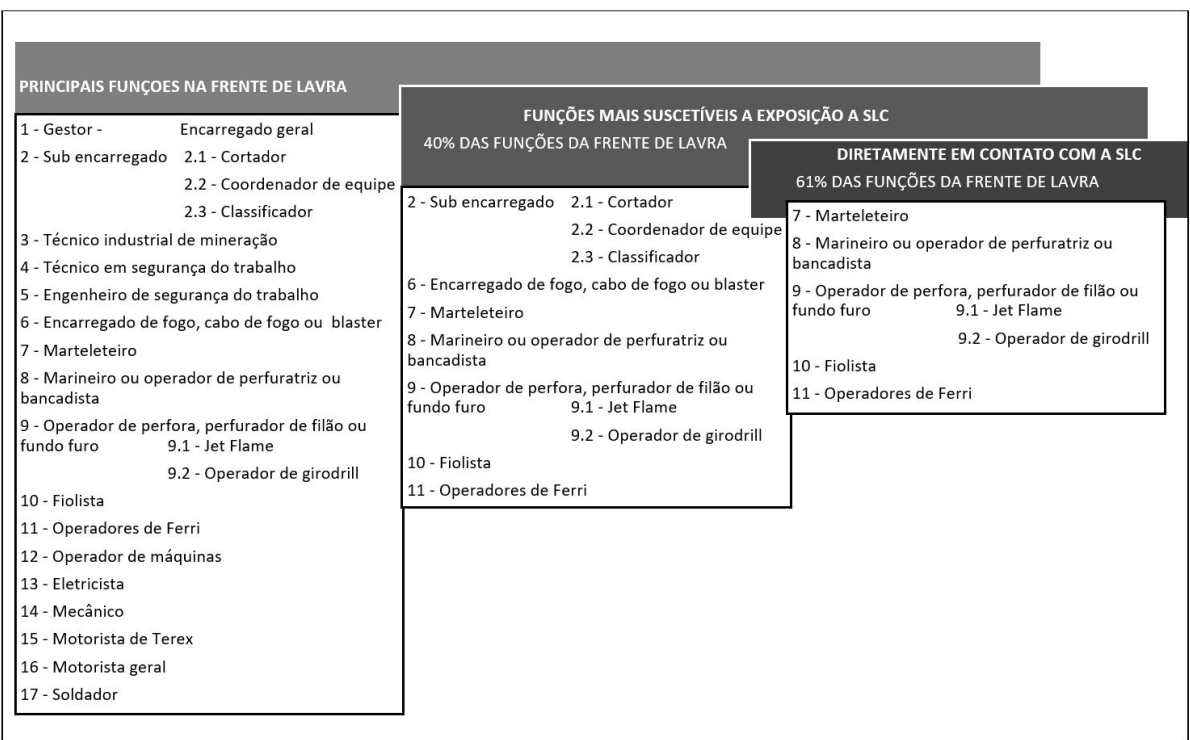

Figura 2. Funções mais suscetíveis a riscos toxicológicos relacionados à inalação de poeira contendo sílica.

Tabela 1. CATs emitidas no setor de mineração na região de estudo 2009-2016.

\begin{tabular}{ccccc} 
Descrição & $\mathbf{2 0 0 9}$ & $\mathbf{2 0 1 0 - 2 0 1 5}$ & $\mathbf{2 0 1 6}$ & Total \\
\hline Típico & 80 & 1167 & 340 & 1587 \\
\hline Trajeto & 14 & 200 & 49 & 263 \\
\hline Doença & 2 & 32 & 20 & 54 \\
\hline Total & 96 & 1399 & 409 & 1904 \\
\hline Silicose & $\mathbf{1}$ & $\mathbf{2 2}$ & $\mathbf{4}$ & $\mathbf{2 7}$ \\
\hline
\end{tabular}

Fonte: Sindimármore/ES. 2019.

doença"man-made" (feita pelo homem), capaz de causar grande sofrimento, perda de qualidade de vida ou até a morte. Todavia, na maioria dos casos, é uma doença incapacitante para a qual não existe um tratamento eficaz, portanto os esforços para o seu controle devem ser aplicados na prevenção primária ${ }^{18}$.

Como princípio básico da prevenção, não somente a poeira pode ser controlada, mas em algumas circunstâncias o processo de trabalho pode ser alterado de modo que não forme poeira, modificando os métodos de trabalho na perfuração de rochas nas indústrias de extração de minerais, substituindo o método de perfuração a seco pelo processo de perfuração úmido, bem como o uso de instrumentos de amostragem de poeiras e de técnicas de exame de pó, para certificação de que a exposição a poeiras esteja abaixo dos limites de tolerância.

As medidas de controle são normatizadas a todas as atividades de risco e devem ser adotadas nos processos envolvidos na extração mineral. Capacitação é palavra de ordem, os procedimentos operacionais claros e bem definidos garantem maior segurança na execução de cada atividade, a substituição dos equipamentos e tecnologias por equivalentes mais modernos e seguros visa isolar as fontes emissoras, evitando exposição. Assim, as medidas prioritárias também estão vinculadas à forte redução do tempo de exposição e implantação ampla de medidas de controle ambiental.

Reduzir a exposição também depende de um processo contínuo e progressivo de vigilância, objetivando maximizar a proteção quanto à manipulação de material silicogênico ${ }^{19}$. Cabe ao engenheiro de segurança e aos demais membros do SESMT ${ }^{20}$ (Serviço Especializado em Engenharia de Segurança e Medicina do Trabalho - NR 4) o gerenciamento de todos os riscos presentes nas diversas atividades de mineração para que se garanta ao trabalhador um 
ambiente seguro e saudável. A gestão da Segurança e Saúde no Trabalho (SST) visa reduzir os riscos de acidentes, atua na promoção da saúde e busca a satisfação dos trabalhadores, melhorando os resultados operacionais e a imagem das organizações, porém, na prevenção, deve-se ressaltar que um aspecto importante é o envolvimento do trabalhador; não basta alertar para o uso dos EPIs adequados, é necessário orientar e fiscalizar. A mudança dessa situação está mais ligada à adoção de procedimentos econômicos e políticos do que medidas individuais ${ }^{21}$.

A emissão da CAT é muito importante, principalmente o completo e exato preenchimento do formulário, tendo em vista as informações nele contidas não apenas do ponto de vista previdenciário, estatístico e epidemiológico ${ }^{22}$, mas também trabalhista e social; elas são de extrema importância para dar suporte às ações de prevenção e principal ferramenta de estatísticas de acidente de trabalho da Previdência Social.

O INSS/ES acompanha os acidentes considerando também os aspectos qualitativos. $O$ setor de mineração responde por aproximadamente $20 \%$ das ações regressivas ajuizadas no estado e as ações regressivas acidentárias do INSS possuem eficácia punitiva-pedagógica contribuindo para a prevenção de futuros acidentes nas pedreiras.

Através de uma equipe técnica especializada, o Sindimármore auxilia na vigilância do combate à exposição de trabalhadores no processo de extração a seco nas pedreiras e nos casos de ilegalidades, faz denúncias e propõe ação judicial tanto para cobrar direitos dos trabalhadores da categoria como para adequar o ambiente laboral. Porém, a fiscalização dos lugares de trabalho é atribuição dos órgãos públicos. Por outra parte, o sindicato desenvolve atividades específicas para os trabalhadores referentes à prevenção da silicose, procurando levar também conhecimentos: i) impressos referentes à prevenção são folhetos, revistas em quadrinhos, cartazes; ii) realiza debates, palestras, encontros; iii) mantém o site atualizado e interage através de redes sociais. Sobre a questão da vigilância, o Sindimármore faz visitas às empresas (mediante autorização) e, observando algum desacordo com a lei, a entidade sindical realiza a denúncia aos órgãos competentes, tais como: MPT; MPF; Delegacia do Trabalhador; DNPM; e outros. O Sindimármore, visando eliminar a perfuração e o corte de rochas a $\operatorname{seco}^{23}$, também participa de duas comissões tripartites para melhoramento do setor, propondo melhorias na reformulação de texto em algumas NR, a exemplo do Anexo I da NR 11; NR 22; e outras pertinentes ao setor.

O Banco Nacional de Desenvolvimento Econômico e Social (BNDES), dentro da Política Socioambiental para o Setor de Mineração, estabelece políticas específicas, que adaptam as orientações gerais às particularidades de cada atividade. A Política Socioambiental para o Setor de Mineração formaliza diretrizes e critérios que balizam a concessão de apoio financeiro a empreendimentos do setor, em complemento às políticas transversais do sistema BNDES e à legislação vigente. Neste contexto, as diretrizes, critérios e práticas para o setor contemplam as questões de saúde e segurança do trabalhador; aspectos como a existência de política e sistema de saúde e segurança do trabalho, com divulgação e capacitação para empregados e terceirizados, são considerados na análise ${ }^{24}$.

\section{DISCUSSÃO}

No processo de trabalho na explotação de granitos ornamentais, observam-se condições insalubres às que os trabalhadores acabam tendo que se submeter, colocando a própria vida em risco. Observam-se também precários procedimentos de trabalho; a pressão dos prazos pelos principais setores demandantes, principalmente referente ao bloco para exportação: e o acelerado processo produtivo. Contudo, para prevenir e controlar as doenças relacionadas ao trabalho que podem levar o trabalhador à incapacidade ou à morte é necessário intervir ${ }^{25}$.

Clinicamente, a silicose se expressa na forma de dificuldades respiratórias, tonturas, fraquezas e náuseas, chegando a incapacitar o trabalhador ${ }^{26}$. Porém, para muitos trabalhadores não existe o reconhecimento da relação entre morbidade e atividade ocupacional; assim, é difícil associar a relação entre sua atividade laboral e seus problemas de saúde. $O$ trabalhador não estabelece facilmente um nexo causal entre os sintomas vividos por ele e sua atividade de trabalho, ou mesmo os fatores de exposição cotidiana não são considerados em um primeiro 
momento, e quando essa associação é finalmente feita, persiste o medo em reclamar por sua condição de saúde, arriscando-se ao indesejado afastamento das funções ou à perda do seu emprego ${ }^{27}$.

Entre 2009 e 2016, constatou-se que o mercado mineral vem passando por mudanças tecnológicas de processos em unidades de produção, porém, no Espírito Santo, em relação ao número de pedreiras em operação, essas mudanças não chegaram a todos. A maioria das pedreiras na região noroeste ainda utiliza processo arcaicos na rotina de trabalho da explotação de granitos ornamentais; faltam fiscalização, investimentos e incentivos.

Em efeito, para incorporar tecnologias que ajudem a prevenir a inalação de sílica por parte dos trabalhadores, seria preciso investir no uso da perfuratriz pneumática com processo umidificado para perfurar a prancha e o uso da máquina de fio diamantado para o cortar o filão. Essas ações preventivas são fundamentais para neutralizar o particulado, antes sempre presente nessas atividades. Observamos que o investimento em novas tecnologias foi uma ação bemsucedida adotada pela empresa nas pedreiras visitadas nos municípios de Barra de São Francisco eVila Pavão, ES. Em pedreiras com investimento tecnológico inserido no processo de produção, as funções requerem capacitação específica para a operação das máquinas e menos contato com a poeira; a adoção de máquinas exige do operador conhecimento técnico. O perfurador de filão e o marteleteiro são as funções com maiores riscos de exposição relacionados à sílica na explotação de rochas ornamentais. Nas duas pedreiras observadas, apenas um homem opera a perfuratriz pneumática com processo umidificado de até 4 martelos, retirando da praça de trabalho 3 marteleteiros. No entanto, devido ao alto custo dos investimentos, algumas máquinas tornam-se pouco acessíveis e em muitas pedreiras o trabalho é degradante, insalubre, precário e clandestino, e muitas pedreiras continuam a executar a perfuração a seco, indo contra o estabelecido pela NR 22 (Segurança e saúde ocupacional na mineração).

Irregularidades também ocorrem quando não são devidamente feitas: a) a emissão da CAT junto ao Ministério da Previdência; $b$ ) a notificação compulsória de acidentes do trabalho e de doenças ocupacionais para o Ministério da Saúde; e c) a notificação compulsória de acidentes do trabalho e de doenças ocupacionais para a Vigilância em Saúde ou Sanitária nos municípios, ocorrendo uma subnotificação dos casos. No contexto laboral da mineração, com relevantes dados estatísticos, que vão contra a integridade física e mental, as lentas mudanças transformam os trabalhadores em meras peças de substituição ${ }^{28}$.

Todavia, nas pedreiras observadas, foram verificadas algumas intervenções objetivando a prevenção de riscos à saúde dos trabalhadores: sistematicamente é abordada no diálogo diário de segurança (DDS) a necessidade do processo umidificado, que diminui a exposição e a inalação de poeiras respiráveis contendo a sílica livre cristalina. Uma outra estratégia rotineira adotada é a promoção de ações de prevenção e controle do ambiente de trabalho, tais como a instalação de placas alertando que a área contém poeira de sílica, identificando o risco através de pictogramas de perigo; palavras de advertência; frases de perigo e frases de precaução.

Os sindicatos patronais e dos trabalhadores e a Fundacentro/ES possuem uma parceria para difundir o Programa Nacional de Eliminação da Silicose (PNES), objetivando "taxa zero de poeira", e promovem ações em prol da conscientização e da eliminação à exposição. Os riscos laborais da atividade em pedreiras foram tema de algumas palestras em escolas da região, visando promover um conhecimento sobre a saúde do trabalhador e os riscos do setor, já que a atividade em pedreira é uma opção para muitos.

A solicitação pelo MTE/ES para implantação de ginástica laboral como instrumento de prevenção foi bem recebida pelos trabalhadores. Orientada por especialista, a ginástica é multiplicada por profissionais da pedreira, realizada diariamente e dividida por praças de trabalho. No livro são registrados os participantes e alguma não conformidade, estando o gestor atento às ocorrências.

Outra abordagem que também traz bons resultados é a Semana Interna de Prevenção de Acidentes de Trabalho na Mineração (Sipatmin), realizada anualmente. A empresa segmenta por setores, são convidados médicos e outros profissionais das áreas de saúde e segurança do 
trabalho, um momento muito rico, quando os trabalhadores assistem a vídeos de casos reais; são depoimentos que alertam quanto a ocorrências de doenças específicas do setor e outras, ocorrem os debates e o encerramento é com algumas atividades lúdicas.

No setor da mineração - uma atividade que envolve grandes riscos, mas cujos baixos índices de emissão da CAT fazem pressupor a subnotificação de acidentes -, a Saúde do Trabalhador não se configura num programa de ação política prioritária.

Mas é preciso conhecer a rotina... Nesse sentido, por meio da atuação profissional nas duas pedreiras estudadas e imersão na rotina de trabalho, foi possível identificar que a habilidade para cada função não foi construída unicamente via cursos e treinamentos formais, mais sim através da capacidade de observação e criatividade dos trabalhadores. O fato de serem moradores da região facilita a formulação de sugestões sobre os métodos de produção utilizados visando a melhorias de produtividade. Eles se veem como parte daquele processo, querem crescer na empresa, procuram produtividade, mas entendem que o risco existe e toda atenção é pouca. A nova geração de funcionários trabalha com mais precaução, enxerga a silicose como uma doença, possui essa percepção quanto ao risco, mas poucos deles associam que a doença se desenvolve ao longo dos anos e que talvez irá acometê-los devido à exposição.

A pedreira não para, são 24 horas por dia, 7 dias por semana, o risco é iminente, perceptível e inserido no cotidiano de muitos profissionais do setor de rochas ornamentais. A silicose é uma doença recorrente no Espírito Santo e ainda é a principal doença pulmonar ocupacional incapacitante.

A vivência na pedreira permitiu ir ao encontro dos achados de $\mathrm{Glina}^{27}$, constatando-se que para o trabalhador o fato de estar doente é visto como nocivo, sentindo-se individualmente desvalorizado e indesejável como profissional e chefe de família. A realidade do setor em relação à problemática da silicose na explotação pode ser outra, porém observa-se a participação de um pequeno percentual de empresas; são necessários investimentos em EPIs e EPCs, implantação de ferramentas objetivando auditorias no processo de trabalho, uma força tarefa no que se refere à fiscalização por parte dos órgãos competentes e uma política compatível com a questão da segurança e saúde nas áreas de mineração, conforme preconiza a recomendação 183 sobre Segurança e Saúde nas Minas da Organização Internacional do Trabalho29. Mais concretamente, observa-se a necessidade de incentivar o investimento em capacitação de mão de obra qualificada e em tecnologias de ponta capazes de facilitar o controle da silicose. Uma mudança que urge em prol da saúde do trabalhador do setor de explotação de rochas ornamentais.

\section{REFERÊNCIAS}

1. Brasil. Ministério da Saúde do Brasil. Organização Pan-Americana da Saúde no Brasil. Doenças Relacionadas ao Trabalho: Manual de procedimentos para os serviços de saúde. Brasília: Ministério da Saúde do Brasil, 2001. (Série A. Normas e Manuais Técnicos; n. 114).

2. World Health Organization. Silica, some silicates, coal dust and para-mid fibrils. Working Group on the Evaluation of Carcinogenic Risks to Hurnans. Lyon: International Agency for Research on Cancer; 1997.

3. Terra-Filho M, Santos UP. Silicosis. J Bras Pneumol. 2006;32(Suppl. 2):S41-7. http://dx.doi.org/10.1590/ S1806-37132006000800008. PMid:17273597.

4. Costa AF, Costa BFM. Segurança e saúde no trabalho: cidadania, competitividade e produtividade. Rio de Janeiro: Qualitymark Editora, 2004.

5. Mendes R. Patologia do Trabalho. 2. ed. Rio de Janeiro: Atheneu; 2002. Vol. 2.

6. Brasil. Departamento Nacional de Produção Mineral. Sumário Mineral. Brasília:DNPM; 2016. (Coordenadores Thiers Muniz Lima, Carlos Augusto Ramos Neves).

7. Azevedo RG. Histórico da extração de rochas ornamentais no estado do Espírito Santo [monografia]. Santa Teresa, Espírito Santo: Escola Superior São Francisco de Assis; 2005. 103 f. 
8. Brasil. Ministério do Trabalho e Emprego. Portaria n.99, de 19 de outubro de 2004. Proíbe o processo de trabalho de jateamento que utilize areia seca ou úmida como abrasivo. Diário Oficial da União. Brasília, 21 de outubro de 2004. [citado em 17 out 2017]. Disponível em: http://www.trtsp.jus.br/geral/tribunal2/ ORGAOS/MTE/Portaria/P99_04.html

9. Brasil. Ministério da Economia. Política Nacional de Segurança e Saúde do Trabalhador. Versão 12/11/2004 pronta após sugestões do Seminário Preparatório, dos AFTs e das DRTs. Brasília, DF; 2004. [citado em 17 out 2017]. Disponível em: http://www.previdencia.gov.br/arquivos/office/3_081014-105206-701.pdf

10. Algranti E, Handar Z, Ribeiro FSN, Bom AMT, Santos AMA, Bedrikow B. Exposición a sílice y silicosis en el Programa Nacional de Eliminación de Silicosis en Brasil (PNES). Cienc Trab. 2004;6(11):1-13.

11. Kauppinen T. Assessment of exposure in occupational epidemiology. Scand J Work Environ Health. 1994;20(Spec No):19-29. PMid:7846489.

12. Azevedo RG. Silicose na explotação de rochas ornamentais [dissertação]. Vila Velha: Centro Universitário Vila Velha; 2009.

13. Moulin MGB, Minayo-Gomez C. Pedras sobre vidas: vítimas e viúvas na indústria de mármore em Itaoca (ES). Cien Saude Colet. 2008;13(4):1361-9. http://dx.doi.org/10.1590/S1413-81232008000400034. PMid:18813637.

14. Gibbs G. Análise de dados qualitativos. Porto Alegre: Artmed; 2009.

15. Brasil. Código de Mineração (1967). Código de Mineração e legislação correlata. 2. ed. Brasília: Senado Federal, Subsecretaria de Edições Técnicas, 2011. (Coleção ambiental; v. 2).

16. Castro NF, Freire LC. Segurança e Saúde na Produção de Rochas Ornamentais. In: IX Simpósio de Rochas Ornamentais do Nordeste. 2016 abr 10-13; João Pessoa, PB. Rio de Janeiro: CETEM/MCTIC; 2016. [citado em 17 out 2017]. Disponível em: www.cetem.gov.br/images/congressos/2016/STRO202.pdf

17. Azevedo RG. Silicose: prevenção da ocorrência em trabalhadores do setor de rochas ornamentais em pedreiras do estado do Espírito Santo [monografia]. Mato Grosso do Sul: Universidade Católica Dom Bosco; 2016.

18. Finocchiaro J. A silicose. In: Finocchiaro J. Causas e prevenção dos acidentes e das doenças do trabalho em São Paulo. São Paulo: Lex Editora; 1976.

19. JassT. Silicose e esclerose sistêmica (síndrome de Erasmus): a importância do reconhecimento da associação entre doenças. Rev Bras Med Trab. 2016;14(1):45-51. http://dx.doi.org/10.5327/Z1679443520161514.

20. Oliveira A. CLT para Rotinas Trabalhistas - Anotada e legislação complementar. 3. ed. São Paulo: Editora Atlas; 2012.

21. Pearce N, Matos E, Boffetta P, Kogevinas M, Vainio H. Occupational exposure to carcinogens in developing countries. Ann Acad Med Singapore. 1994;23(5):684-9. PMid:7847748.

22. Brasil. Presidência da República. Decreto n. ${ }^{\circ}$ 3.048, de 6 de maio de 1999. Aprova o Regulamento da Previdência Social, e dá outras providências. Diário Oficial da União. Brasília, 7 de maio de 1999, p. 50. [citado em 23 out 2017]. Disponível em: http://legislacao.planalto.gov.br/legisla/legislacao.nsf/ Viw_Identificacao/DEC\%203.048-1999?OpenDocument.

23. Brasil. Ministério da Saúde. Secretaria de Atenção à Saúde. Programa Nacional de Eliminação da Silicose, Brasil - Completando uma década. Brasília: Editora do Ministério da Saúde; 2012.

24. Banco Nacional de Desenvolvimento Econômico e Social. Política Socioambiental para o Setor de Mineração do Sistema BNDES [Internet]. [citado em 7 out 2017]. Disponível em: https://www.bndes. gov.br/wps/portal/site/home/quem-somos/responsabilidade-social-e-ambiental/o-que-nos-orienta/ politicas/politica-socioambiental/politica-setorial-mineracao

25. Mendes R. O impacto dos efeitos da ocupação sobre a saúde de trabalhadores. I. Morbidade. Rev. Saúde Pública. 1988 ago;22(4):311-26. http://dx.doi.org/10.1590/S0034-89101988000400007.

26. Cabral LN, Pereira SS, Alves TLB. Degradação ambiental e implicações para a saúde humana decorrentes da mineração: o caso dos trabalhadores de uma pedreira no município de Campina Grande-PB. Hygeia. 2012;8:104-18.

27. Glina DMR. Modelos teóricos de estresse e estresse no trabalho e repercussões na saúde do trabalhador. In: Glina DMR, Rocha LE. organizadores. Saúde mental no trabalho: da teoria à prática. São Paulo: Roca; 2010.

28. Azevedo R G, Vieira C B, Moraes HAB, Siqueira M M. Políticas de Saúde e Segurança do Trabalhador no Estado do Espírito Santo, Brasil. Rev. Bras. Pesq. Saúde. 2016;18(1):62-67. 
29. Brasil. Presidência da República. Casa Civil. Decreto $n^{\circ} 6.270$, de 22 de novembro de 2007. Promulga a Convenção no 176 e a Recomendação no 183 da Organização Internacional do Trabalho (OIT) sobre Segurança e Saúde nas Minas, adotadas em Genebra, em 22 de junho de 1995, pela 85a Sessão da Conferência Internacional do Trabalho. Diário Oficial da União [Internet], Brasília, 22 de novembro de 2007 [acesso em 7 out 2017]. Disponível em: http://www.ilo.org/brasilia/convencoes/WCMS_242756/ lang--pt/index. 